\title{
Trial design of a dome roof for an church
}

\author{
Vadim Yu. Alpatov ${ }^{1, *}$, Oleg Yu. Veremeenko ${ }^{1}$, Andrei A. Sakharov ${ }^{1}$ and Vyacheslav S. \\ Shirokov ${ }^{1}$ \\ ${ }^{1}$ Samara State Technical University Institute of Architecture and Civil Engineering, \\ Molodogvardeyskaya st. 194, 443001 Samara, Russia
}

\begin{abstract}
The paper describes some construction solutions for a metalic dome roof of an orthodox church. The authors describe three alternative variants (with different structural diagrams) of designing its dome framework. The paper introduces ribbed ring-shaped, grid and webbed geodesic dome constructions which are aimed to be used in the same operation conditions. The researchers calculated structural design, strength, proportioning of members and weight index as well as geometrically arranged elements of each dome design structure. Then their general total economic parameters were compared.
\end{abstract}

\section{Introduction}

Dome structures are often used successfully in round buildings [1-6, 11]. Dome roofs are usually designed for buildings of social entertainment (such as circuses and stadiums) and for religious buildings (such as orthodox churches). Dome roofs can be classified according to different characteristics, such as their purpose, design shape, size, rising height, materials used, etc. According to the dome construction, they are divided into ribbed, ribbed ringshaped, webbed, radial beam and grid domes $[3,7]$.

Dome design mostly depends on technical-and-economic properties of its coating [7-9]. Complexity / simplicity of a dome calculations, manufacturing, final fitting-up and so on depend, in their turn, on this dome design. Above all, weight and price of a dome depend on this dome design. We find it possible to estimate efficiency of different dome constructions (being used in certain operation conditions) while applying optimal design theory. For that, we have to set out to calculate the minimum weight of the construction as a parameter optimization problem and to find a solution to the problem. Trial design is most frequently used to point out the most ergonomic dome structure in real life. To do that we need to work out several alternative variants of the construction in question and then to choose the best one taking into account a definite criterion $[5-8,10]$.

\footnotetext{
*Corresponding author: avu75@mail.ru
} 


\section{Calculate economic efficiency of the designed dome structures}

The authors applied the trial design method when constructing a dome roof of the Orthodox Church. While designing this roof the authors chose ribbed ring-shaped, grid and webbed geodesic domes for comparative analysis. The researchers calculated structural design, strength, proportioning of members and weight index as well as geometrically arranged elements of each dome design structure. Geometrical arrangement of the dome different design structures was made while using AutoCAD and SolidWorks software systems. Static analysis of the dome different design structures was made while using LIRA software system. Joint connection deign was made by SolidWorks software system. Dome elements weight and its whole weight was calculated in Excel application. Dome different design structures made by SolidWorks software system can be seen in Figures 1-3.

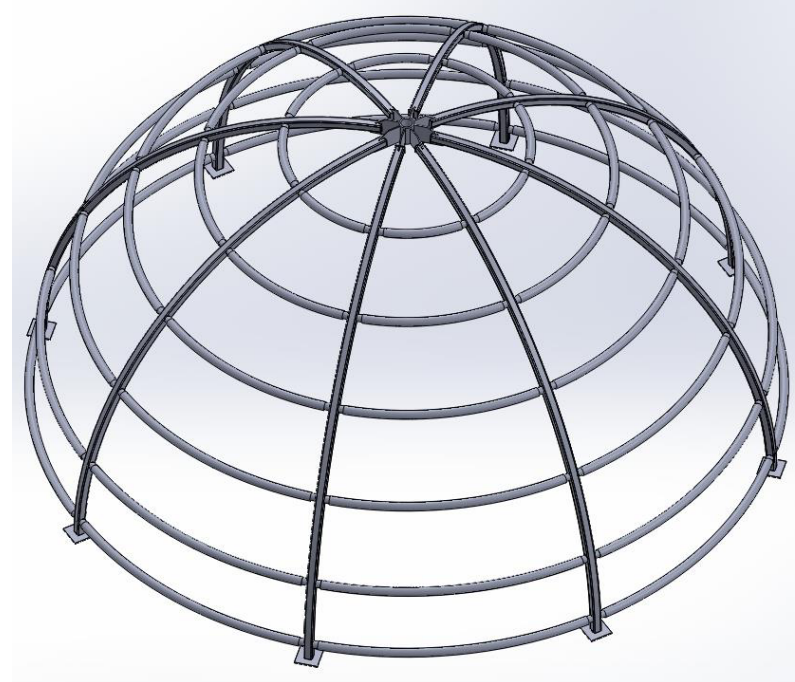

Fig. 1. Ribbed ring-shaped dome.

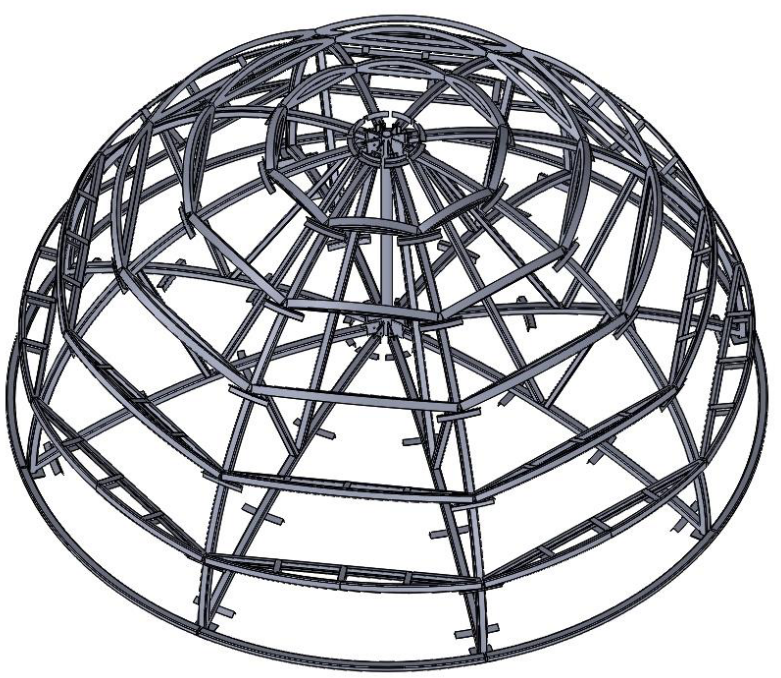

Fig. 2. Grid dome. 


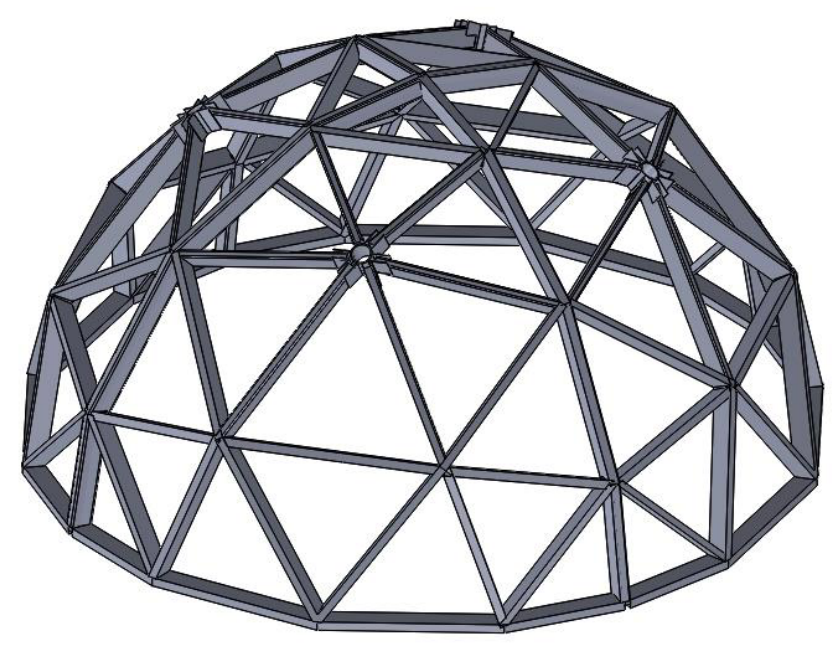

Fig. 3. Webbed geodesic dome.

To calculate economic efficiency of the designed dome structures the authors used Ya.M. Likhtarnikov's methodology [10]. According to this methodology to determine the cost of the construction one has to calculate the construction weight and its elements and units weight , labour hours, transport operation and construction assembling:

$$
T=T^{\text {prdct }}+T^{\text {trnsp }}+T^{\text {inst }}
$$

To calculate labour hours we need to define the necessary amount of carving, bending, drilling, welding, etc. All these calculations depend on the roof elements type (if its rolled stock or sheet), weight and amount. That is why three dome different design structures were calculated and their technical-and-economic properties were compared.

To calculate transport operations it was necessary to decide on the type of assembling, the type of deliverable assemblies and their quantity, to heft assemblies and choose the mode of transportation. To calculate assembling costs it was necessary to decide on the erection method and assembling vehicles and machinery.

While designing these three dome structures the researches did not take into account transport operation and assembling labour input. They found it possible to rely on the cost of materials required for the construction and the cost of its manufacturing (which was based on the required labour hours).

\section{Conclusion}

1. Taking into account the calculated dome different design structures and comparing their technical-and-economic properties the authors come to the conclusion that a ribbed ringshaped dome is the best option.

2. The total cost of assembling a grid dome is $7 \%$ more than that of a ribbed ring-shaped dome.

3. The total cost of assembling a webbed geodesic dome is twice as much compared to that of a ribbed ring-shaped dome. 


\section{References}

1. I.S. Kholopov, V.Yu. Alpatov, V.N. Mochalnikov, N.N. Moiseev, V.Yu. Veschin, Actual problems of metal, timber and plastic constructions developing and modernizing (Civil Engineering and Transport): International Scientific-Technological Conference Materials (SamGASA, Samara, 2002)

2. V.Yu. Alpatov, I.S. Kholopov, A.V. Solovjev, Stroy-info: news bulletin 22(214), 7-10 (2003)

3. A.V. Tur, I.S. Kholopov, M.D. Mosesov, Traditions and innovations in architecture and civil engineering, 70th anniversary scientific and technical conference proceedings (SGASU, Samara, 2013)

4. V.Yu. Alpatov, N.R. Ratzev, A.R. Ratzev, Materialy IX Miedzynarodowej naukowipraktycznej konferencji «Wschodnie partnerstwo - 2013», Budownictwo i architektura: Przemysl. Nauka i studia 32, 40-43 (2013)

5. V.S. Shirokov, V.Yu. Alpatov, Scientific electronic archival depository. URL: http://econf.rae.ru/article/7097 (Reference date: 19.11.2012) (2012)

6. XXI century: building materials, equipment, technologies

7. V.Yu. Alpatov, O.V. Alpatova, A.V. Alpatov, A.A. Belyakova, Scientific Survey 24, 51-56 (2015)

8. V.Yu. Alpatov, S.S. Igoshin, Traditions and innovations in architecture and civil engineering, 67th scientific and technical conference proceedings (SGASU, Samara, 2010)

9. V.Yu. Alpatov, M.I. Balzannikov, I.S. Kholopov, A.A. Lukin, Procedia Engineering 111, 72-81 (2015)

10. Ya.M. Likhtarnikov, Metal structures. Methods of technical economical analisys in design (Stroyizdat, Moscow, 1968)

11. I.S. Kholopov, M.I. Balzannikov, V.Yu. Alpatov, Vestnik SGASU, Town Planning and Architecture 28(47), 225-232 (2012) 